\title{
Assessment of Microbial Growth on the Surface of Materials in Contact with Water Intended for Human Consumption Using ATP Method
}

\author{
MACIEJ SZCZOTKO and ADAM KROGULSKI* \\ Department of Municipal Hygiene, National Institute of Public Health - National Institute of Hygiene, \\ Warsaw, Poland
}

Received 3 February 2010, revised 10 October 2010, accepted 20 October 2010

Abstract

\begin{abstract}
Elaboration of an assessment method for plumbing materials contacting drinking water was the main purpose of this study. The investigation was conducted in 8 week cycles in dynamic conditions using a continuous flow reactor. Microbial growth was measured indirectly by a bioluminescence technique (ATP assay). Every week swabs from the surface of tested materials (polypropylene and different types of polyethylene), from the domestic market were collected and the level of bioluminescence was examined. The results obtained from the surface of tested materials were repeatable and clearly approximated those obtained from the surface of a negative control (stainless steel, low susceptibility for microbial growth). The level of bioluminescence (ATP) on the surface of positive control (paraffin, high susceptibility for microbial growth) was many times higher than that observed on other materials. The presented investigation was the main part of a validation process, which in short time will serve to initiate a complete assessment system for organic materials contacting drinking water.
\end{abstract}

K e y w ord s: ATP, bioluminescence, biofilm, continuous flow reactor, plumbing materials

\section{Introduction}

A biofilm is a characteristic living structure growing on every type of surface contacting the water environment. The occurrence of biofilm on the inner surface of plumbing materials like organic ones (PE - polyethylene, PP - polyprophylene, PVC - polyvinyl chloride, $\mathrm{PB}$ - polybutylene), steel, cast iron pipes and even copper pipes is well known (Kooj van der et al., 1995; Niquette et al., 2000; Zacheus et al., 2000; Camper et al., 2003; Lehtola et al., 2004; Kim et al., 2006). Microorganisms together with organic and inorganic compounds constitute the main part of this dynamic biological structure which is the prevailing microbial lifestyle in natural microenvironments. The majority of microorganisms have good adhesion properties. The structural development of biofilm formation has been described as a sequence of events including attachment, microcolony development and finally, the establishment of distinct structures as previously described (Martiny et al., 2003). At first, the process of the attachment bacteria cells to the surface of a material is reversible. Depending on the size and charge of particle, compensation of ion concentration occurs on both sides of the growing biofilm structure and bacteria forming microcolonies starts to produce organic polymers such as polysaccharides and glycoproteins which is the first stage of the biofilm formation process. Intensive production of polymers allows for permanent attachment to the surface and building of a mature and complicated biofilm structure with diverse microniches. Due to different oxygen, nutrient and metabolite concentration, high level of diversity in microbial communities occurs in every microniche. Depending on specific conditions inside a biofilm structure, microorganisms such as bacteria, fungi, molds, algae, nematodes and protozoans can be found. From among bacteria isolated from cold water biofilms, Pseudomonas sp., Flavobacterium sp. and Acinetobacter sp. are among the most common groups. Bacteria from the genus Legionella represent 35 per cent of microorganisms forming biofilms inside hot water tanks and hot water plumbing systems (McBain et al., 2003; Mampel et al., 2006). Biofilms formed in water distribution networks are known to cause public health problems. Elaboration of a method for the assessment of susceptibility of microbial growth on the surface of materials contacting drinking water may provide new tools for improving water quality for the consumer.

According to EU Directive 89/106/EEC concerning construction products and drinking water Directive 98/83/EC, every material contacting with drinking

\footnotetext{
* Corresponding author: A. Krogulski, 00-791 Warsaw, Chocimska 24, Poland; e-mail: akrogulski@pzh.gov.pl
} 
water should be examined for its susceptibility for microbial growth. Positive results obtained for examined materials or construction products will allow to issue a CE-EAS certificate on the basis of which admission to use materials and products concerned will be granted. Among the members of European Union there is no single, standardized, unified method and assessment criterion for this evaluation. Every country has its own legal regulations and examination methods regarding materials in contact with drinking water. In some countries, for instance in Germany, Great Britain, the Netherlands, Austria and a few more, different testing and assessment methods for microbial enhancement on materials already exist (van der Kooij et al., 2003). The process of unification of this method is difficult and no rational conclusion has yet been found, In Poland there is no official examination method for evaluation of microbial growth on the surface of materials in contact with drinking water. The National Institute of Public Health - National Institute of Hygiene is a Polish institution authorized to issue hygienic certificates based on the results of chemical testing and assessment of chemical composition of product or material. The hygienic certificate entails admission to use a given material or product in contact with drinking water. The completion of documentation with additional results of microbial growth level will improve Polish regulation according to articles of the EU Directives mentioned above.
The purpose of the present study was to elaborate and implement a Polish method for estimating the susceptibility of materials contacting drinking water on microbial growth.

\section{Experimental}

Materials and Methods

Tested materials and products. The assay was conducted on four different pipe materials currently admitted for use in contact with drinking water. Materials included in the investigation were as follows: polypropylene (PP), polyethylene (PE), polyethylene $\mathrm{RC}$ (PP-RC) and a multilayer pipe with an aluminum layer (PE-X-Al). As control positive and negative were used glass plates covered with paraffin (SP) and stainless steel plates (S), respectively. All the samples of materials were tested in two or three repetitions.

Continuous flow reactors. Two continuous flow reactors - UPE (polish specific name) working simultaneously and supplied from cold tap water were used in this investigation. The UPE project was elaborated together with employees of Hydro-Engineering and Hydraulics Department from Environmental Engineering Faculty at Warsaw University of Technology. Figure 1. presents the project of continuous flow reactor in detail. The cylindrical body of UPE (inside diameter was $150 \mathrm{~mm}$, high was $550 \mathrm{~mm}$ ) was made of

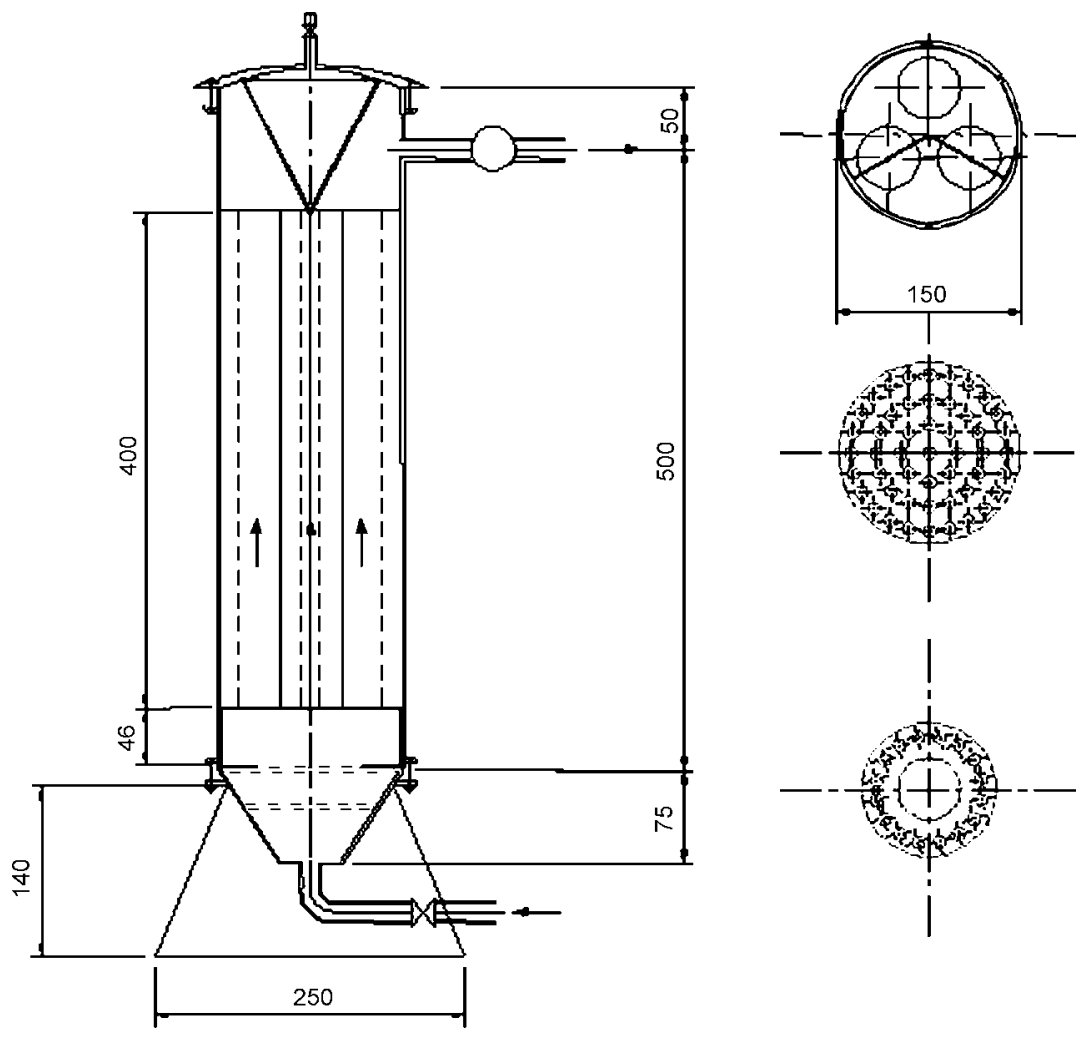

Fig. 1. UPE technical diagram: continuous flow reactor. 
high quality stainless steel with teflon seal. On top of the reactor was a removable cover with venting valve.

Water inlet wire was made of teflon and water pressure was regulated by a ball valve. Inside the reactor, at the bottom, a conical diffuser with two partitions was located. A special sample stand made of stainless steel was placed in vertical position inside the cylinder. The water outlet with water meter was located on the side of the UPE about $50 \mathrm{~mm}$ below the top. The water flow proceeded from the bottom to the top of reactor so that the reactor could be filled with water evenly and this flow direction protected against the mixing of inlet and outlet water. The average water flow was established at $1 \mathrm{~m}^{3} /$ day.

ATP assay. Luminometer HY-LiTE $2^{\circledR}$ (MERCK) was applied for the determination of ATP level in swabs taken from the surface of tested materials and controls. A sample measured with this instrument is indicated on the display in relative light units (RLU). The RLU value is directly proportional to the quantity of ATP in the sample tested and therefore also directly proportional to contamination with biological material. The luminometer has a built-in temperature compensation and calibration self check. The test system consists of ready tests, the "Pens" with proper dose of reagents so test results can be obtained in a short time. The linear working range for HY-LiTE $2^{\circledR}$ is 0-99.000 RLU (0-5.00 log 10 RLU). The tested sensitivity of the used luminometer is 1 RLU.

Sample preparation and testing procedure. Every sample of material $\left(80 \mathrm{~cm}^{2}\right.$ surface) before examination was mechanically cleaned, treated with $70 \%$ ethanol and washed with deionized water. After this pretreatment swabs from the surface were collected for the verification of ATP level on day 0. After the first assay all samples were placed on a stand inside the continuous flow reactor. The examination was conducted during 60 days and every seven days the ATP concentration from the surface of tested pipe materials and controls was determined. The swabs were taken from $2 \mathrm{~cm}^{2}$ surface of every sample in five repetitions. Temperature of water and flow strength was monitored throughout the whole examination period.

\section{Results and Discussion}

The main principles of the presented method are elaborated on the basis of techniques used in food industry which is wide field for bioluminescence assays used to determine microbial contamination in a specific food product, surfaces contacting with food and hygiene monitoring (Hawronskyj and Holah, 1997; Breeuwer and Abee, 2000; Aycicek et al., 2006; Bzducha, 2007). Conventional methods of microbiological analysis, such as plate cultures, swabbing, wash-and-rinse and other are time-consuming and laborious. Time is a very important part of the production cycle. Since the results are obtained 48 or $72 \mathrm{~h}$ after sample collection, it is impossible to undertake corrective actions (Cais-Sokolinska and Pikul, 2008). When the cleanliness status of the examined objects is monitored by bioluminescence methods using findings concerning cell biochemistry and the physicochemical properties of microorganisms (Cho and Yoon, 2007), safety assurance is much more facilitated (Larson et al., 2003). An important advantage of this method is short time from collecting a sample to the result, high sensitivity and easy performance (Squirrell et al., 2002).

ATP is an energy carrier in all living organisms, linking catabolism and biosynthesis. In the presented method the RLU values, directly proportional to the quantity of Adenosinetriphosphate (ATP), were the main biomass parameters for testing the growth - promoting properties of materials. This type of assay has a number of advantages over the use of other parameters of assessment the presence of microorganisms, as it: includes all active microorganisms, is absent in dead (inactive) microorganisms, enables rapid testing, has low detection limit.

The principle of this assay is based on the firefly luciferine - luciferase reaction, which results in the emission of one quantum of light for each molecule of ATP hydrolyzed.

Results based on bioluminescence assay presented below are a consequence of research on the growtpromoting properties of materials in contact with

Table I

Bioluminescence level on the surface of polypropylene pipe material (PP) placed in UPE1.

\begin{tabular}{|c|c|c|c|c|c|c|c|c|c|}
\hline Material & \multicolumn{9}{|c|}{ Bioluminescence level during successive weeks of conducted assay [RLU/ $\left.\mathrm{cm}^{2}\right]$} \\
\hline Weeks & 0 & I & II & III & IV & $\mathrm{V}$ & VI & VII & VIII \\
\hline $\mathrm{PP}(1)$ & 10 & 90 & 48 & 234 & 330 & 400 & 324 & 549 & 109 \\
\hline PP (2) & 12 & 94 & 34 & 90 & 219 & 145 & 70 & 159 & 56 \\
\hline PP average & 11 & 92 & 41 & 162 & 274 & 272 & 197 & 354 & 82 \\
\hline $\mathrm{PC}^{*}$ & 16 & 16834 & 9167 & 12834 & 13125 & 20834 & 36500 & 43667 & 32500 \\
\hline $\mathrm{NC}^{*}$ & 15 & 44 & 62 & 209 & 113 & 49 & 74 & 254 & 75 \\
\hline
\end{tabular}

* PC - Positive Control, NC - Negative Control 
Table II

Bioluminescence level on the surface of polyethylene pipe material (PE-80) placed in UPE1.

\begin{tabular}{|c|c|c|c|c|c|c|c|c|c|}
\hline \multirow{2}{*}{$\begin{array}{c}\text { Material } \\
\text { Weeks } \\
\end{array}$} & \multicolumn{9}{|c|}{ Bioluminescence level during successive weeks of conducted assay [RLU/cm²] } \\
\hline & 0 & $\mathrm{I}$ & II & III & IV & $\mathrm{V}$ & VI & VII & VIII \\
\hline PE-80 (1) & 12 & 159 & 39 & 43 & 195 & 188 & 74 & 75 & 82 \\
\hline PE-80 (2) & 10 & 164 & 38 & 35 & 170 & 69 & 95 & 67 & 42 \\
\hline PE-80 average & 11 & 161 & 38 & 39 & 182 & 128 & 84 & 71 & 62 \\
\hline $\mathrm{PC}^{*}$ & 16 & 16834 & 9167 & 12834 & 13125 & 20834 & 36500 & 43667 & 32500 \\
\hline $\mathrm{NC}^{*}$ & 15 & 44 & 62 & 209 & 113 & 49 & 74 & 254 & 75 \\
\hline
\end{tabular}

* PC - Positive Control, NC - Negative Control

Table III

Bioluminescence level on the surface of polypropylene (PP-RC) pipe materials placed in UPE2.

\begin{tabular}{|c|c|c|c|c|c|c|c|c|c|}
\hline \multirow{2}{*}{$\begin{array}{c}\text { Material } \\
\text { Weeks }\end{array}$} & \multicolumn{9}{|c|}{ Bioluminescence level during successive weeks of conducted assay $\left[\mathrm{RLU} / \mathrm{cm}^{2}\right]$} \\
\hline & 0 & I & II & III & IV & $\mathrm{V}$ & VI & VII & VIII \\
\hline PP-RC (1) & 12 & 22 & 42 & 50 & 94 & 86 & 60 & 535 & 32 \\
\hline PP-RC (2) & 15 & 59 & 67 & 49 & 143 & 88 & 58 & 426 & 50 \\
\hline PP-RC (3) & 11 & 22 & 48 & 67 & 105 & 71 & 58 & 808 & 48 \\
\hline PP-RC average & 13 & 34 & 52 & 55 & 114 & 82 & 59 & 590 & 43 \\
\hline $\mathrm{PC}^{*}$ & 23 & 12334 & 10450 & 38834 & 39832 & 23834 & 38667 & 41667 & 28250 \\
\hline $\mathrm{NC}^{*}$ & 16 & 42 & 115 & 197 & 159 & 187 & 54 & 159 & 97 \\
\hline
\end{tabular}

* PC - Positive Control, NC - Negative Control

drinking water conducted since 2006 (Szczotko et al., 2008; Szczotko et al., 2009). The applicability of the continuous flow reactor prototype (UPE) was confirmed in 2007. Optimal environmental conditions and duration of this test ( 8 weeks) were defined and significant differences in the velocity of microbial growth on the surface of few materials contacting drinking water were demonstrated. On the basis of the obtained results optimal time and specific condition of test method were established.

We examined and compared the biofilm formation process on the surface of a few materials contacting drinking water. All the results demonstrated in the tables below were obtained during examination conducted in 2008 and are presented in RLU/ $\mathrm{cm}^{2}$ (Table I).

At the end of the second week of examination of bioluminescence measured on the surface of both PP samples was similar. Beginning from the third week, the results on the surface of PP (1) were over twice as high as on the surface of PP (2). The results of the first assay (week 0) presented an appropriate method of pretreatment applied and amounted $10 \mathrm{RLU} / \mathrm{cm}^{2}$ and $12 \mathrm{RLU} / \mathrm{cm}^{2}$ for PP (1) and PP (2), respectively. After the first week of examination, the bioluminescence level increased almost ten times. In successive weeks microbial growth was less rapid. The highest results were obtained after the seventh week when the bioluminescence level reached $549 \mathrm{RLU} / \mathrm{cm}^{2}$ on the surface of PP (1) and $219 \mathrm{RLU} / \mathrm{cm}^{2}$ on the surface of PP (2). The average end result for PP samples was $82 \mathrm{RLU} / \mathrm{cm}^{2}$, this being similar to the result obtained on the surface of stainless steel negative control. Microbial growth on the surface of paraffin negative control was very rapid and bioluminescence measured in the eighth week amounted to $32500 \mathrm{RLU} / \mathrm{cm}^{2}$ (Table II).

The results obtained in swabs taken from the surface of both PE materials were similar except for those received in the fifth week. The highest microbial growth was detected in the first week of the experiment and in the following weeks the bioluminescence level slightly decreased. The average end result for PE samples was $62 \mathrm{RLU} / \mathrm{cm}^{2}$. Results obtained during eight weeks of examination clearly showed a similarity between PE pipe materials and stainless steel negative control. Bioluminescence measured on the surface of negative control sample was five hundred times higher (Table III).

Fluctuations of the bioluminescence level measured on the surface of PP-RC pipes samples during eight weeks of examination were insignificant. Only in the seventh week the results from all three samples were high but decreased just one week later. The average level of bioluminescence at the end of the investigation amounted to $43 \mathrm{RLU} / \mathrm{cm}^{2}$ and was lower with reference to results obtained from the surface of the negative control sample. Microbial growth on positive and negative samples placed inside both continuous flow reactors (UPE1 and UPE2) were very similar (Table IV).

Changes in the bioluminescence level measured from swabs taken from the surface of multilayer pipes 
Table IV

Bioluminescence level on the surface of multilayer polyethylene and aluminum pipe material (PE-X-Al) placed in UPE2

\begin{tabular}{|c|c|c|c|c|c|c|c|c|c|}
\hline \multirow{2}{*}{$\begin{array}{c}\text { Material } \\
\text { Weeks }\end{array}$} & \multicolumn{9}{|c|}{ Bioluminescence level during successive weeks of conducted assay $\left[\mathrm{RLU} / \mathrm{cm}^{2}\right]$} \\
\hline & 0 & I & II & III & IV & V & VI & VII & VIII \\
\hline PE-X-Al (1) & 11 & 21 & 70 & 46 & 275 & 134 & 838 & 314 & 162 \\
\hline PE-X-Al (2) & 16 & 21 & 132 & 32 & 198 & 290 & 1022 & 465 & 214 \\
\hline PE-X-Al (3) & 13 & 50 & 61 & 49 & 300 & 260 & 572 & 273 & 194 \\
\hline PE-X-Al average & 13 & 31 & 88 & 42 & 258 & 228 & 811 & 351 & 190 \\
\hline $\mathrm{PC}^{*}$ & 23 & 12334 & 10450 & 38834 & 39832 & 23834 & 38667 & 41667 & 28250 \\
\hline $\mathrm{NC}^{*}$ & 16 & 42 & 115 & 197 & 159 & 187 & 54 & 159 & 97 \\
\hline
\end{tabular}

* PC - Positive Control, NC - Negative Control

(PE-X-Al) were characterized by slow increase during the first six weeks of investigation. In the sixth week bioluminescence values collected from all three pipe samples were the highest and the average value was $811 \mathrm{RLU} / \mathrm{cm}^{2}$. During the next two weeks all values significantly decreased and the average bioluminescence in swabs taken from the surface of the tested samples was $190 \mathrm{RLU} / \mathrm{cm}^{2}$ at the end of examination. The result obtained from the surface of the negative control was slightly lower.

The temperature of water flowing through both continuous flow reactors was relatively stable and average values were between $20.6^{\circ} \mathrm{C}$ and $21.2^{\circ} \mathrm{C}$ for UPE1 and UPE2, respectively.

On the basis of the obtained results relatively low susceptibility for microbial growth of tested material samples was observed. The presented changes in the bioluminescence level on the surface of each material approximated the values obtained from the surface of negative control (stainless steel). All presented results were low with reference to positive control (paraffin plates) which showed even a few hundred times higher bioluminescence level. The data obtained indicated that applied laboratory equipment and the test method developed were sufficient to assess the growth-promoting properties of materials contacting drinking water. Both positive and negative control materials are suitable for this method (Rosmaninho et al., 2007). Owing to a very sensitive bioluminescence test method applied in this investigation, it was possible to conduct precise monitoring of biofilm growth since the first days of its formation process and afterwards - during the entire 8 week study period. Each assay was relatively simple and results were obtained in a very short time. The presented testing method is currently a proposal for solving the problem of microbiological contamination of drinking water in water distribution systems, particularly in case of different plumbing materials. Several EU countries already have legal regulations concerning the assessment of growt-promoting properties of materials con- tacting with water and laboratory test methods have been put into practice for many years in national scientific centers and service laboratories.

In the United Kingdom the MDOD (Mean Dissolved Oxygen Difference) according to has become the standard method (BS 6920-2.4). In this test additional oxygen consumption in the presence of the material to be tested is used as parameter for microbiological activity. The method has been used for several decades and a great deal of materials have been tested. Typical MDOD values range from about $0.5 \mathrm{mg} / 1$ (glass - negative control) to values of $8 \mathrm{mg} / \mathrm{l}$ for paraffin wax (positive control). Materials with a MDOD value above $2.3 \mathrm{mg} / \mathrm{l}$ are considered not suitable for use in contact with water intended for human consumption.

The slime production test according to DVGW Technical Standard W 270 test developed in Germany has also been used for nearly 25 years. This method is applied in a dynamic system, with sheets of materials in contact with continuously flowing tap water. The volume of slime on the surface of the tested material is used as a biomass parameter. Typical SP values range from less than $0.1 \mathrm{ml}$ (stainless steel - negative control) to more than $15 \mathrm{ml}$ on solvent - containing bitumen or plasticized PVC. Materials with SP value above $0.1 \mathrm{ml}$ are considered unsuitable for use in contact with drinking water.

In the Netherlands BPP (Biomass Production Potential) Test has been elaborated. In this test adenosinetriphosphate (ATP) is used as parameter for active biomass and test is carried out as a static test without replacement of the water (van der Kooij et al., 2001). ATP method enables the detection of very low concentration of microorganisms and the analysis can be conducted within a few minutes. ATP analysis is also used for determining the biofilm concentration on the walls of distribution system pipes and in the biofilm monitor for determining the Biofilm Formation Rate (BFR) values of drinking water.

An alternative standardized method for testing of pipe materials in contact with drinking water has recently 
been published in Austria (Önorm B 5018-1,2002). Pipes are fixed in a vertical position and their bottom ends are closed by mean of foamed PE - stoppers. Next, pipes are filled with tap water and incubated at $22^{\circ} \mathrm{C}$ with weekly water replacement. The water is aerated from below. Heterotrophic Plate Count (HPC) is determined according to EN ISO 6222 at $22^{\circ} \mathrm{C}$ after one, two and three months of incubation. At the end of the test biofilm grown on the inner pipe wall is assessed using the ATP - method. The evaluation is performed in relation to a negative (glass pipe) and positive control ( $\mathrm{PVC}-\mathrm{P}$ tube). Pipes are not recommended for use in contact with drinking water if the HPC value of the test water is 10 times higher than in the glass control or when biofilm on the pipe specimen is 5 times higher than in the glass control.

A variety of methods for testing of products impede the uniform assessment procedures and the development of European market. In this situation there is a great need to put into practice a Polish testing method with its own specific requirements.

\section{Literature}

Aycicek H., U. Oguz and K. Karci. 2006. Comparison of results of ATP bioluminescence and traditional hygiene swabbing methods for the determination of surface cleanliness at a hospital kitchen. Int. J. Hyg. Environ.-Health 209: 203-206.

Breeuwer P. and T. Abee. 2000. Assessment of viability of microorganisms employing fluorescence techniques. Int. J. Food Microbiol. 55: 193-200.

BS 6920-2.4, British Standard. 2000. Suitability of nonmetallic products for use in contact with water intended for human consumption with regard to their effect on the quality of water. Methods of test. Growth of aquatic microorganisms test. http://standardsdevelopment.bsigroup.com/Home/Committee/ 50002182? type $=$ m\& field $=$ Status

Bzducha A. 2007 Rapid methods for microorganism identification in food (in Polish). Medycyna Wet. 63: 773-777.

Cais-Sokolinska D. and J. Pikul. 2008. Using the bioluminescence and microbiological contact methods in sustaining a proper hygienic level in food processing plants. Acta Sci. Pol. Technol. Aliment. 7: 53-60.

Camper A.K., K. Brastrup, A. Sandvig, J. Clement, C. Spencer and A.J. Capuzzi. 2003. Effect of distribution system materials on bacterial regrowth. J. Am. Water Works Assoc. 95: 107-121.

Cho M. and J. Yoon. 2007. The application of bioluminescence assay with culturing for evaluating quantitative disinfection performance. Water Res. 41: 741-746.

Council Directive (89/106/ECC) of 21 December 1988 on the Approximation of Laws, Regulations and Administrative Provisions of the Member States Relating to Constructions Product. http://ec.europa.eu/enterprise/sectors/construction/documents/ legislation/cpd/index en.htm -

Council Directive $9 \overline{8} / 83 / \mathrm{EC}$ of 3 November 1998 on the quality of water intended for human consumption. http://ec.europa.eu/ environment/water/water-drink/index en.html -

DVGW W270, Microbial Enhancement on Materials to Come into Contact with Drinking Water - Testing and Assessment. 2007. http://www.dvgw.de/
Hawronskyj J.-M. and J. Holah. 1997. ATP a universal hygiene monitor. Trends Food Sci. Technol. 8: 79-84.

Kim H., J. Ryu and L.R. Beuchat. 2006. Attachment of and biofilm formation by Enterobacter sakazakii on stainless steel and enteral feeding tubes. Appl. Environ. Microbiol. 72: 5846-5856.

Larson E.L., A. Aiello, C. Gomez-Duarte, S.X. Lin, L. Lee, P. Della-Latta and C. Lindhardt. 2003. Bioluminescence ATP monitoring as a surrogate marker for microbial load on hands and surfaces in the home. Food Microbiol. 20: 735-739.

Lehtola M., J. Juhna, I. Miettinen, T. Vartiainen and P.J. Martikainen. 2004. Formation of biofilms in drinking water distribution networks, a case study in two cities in Finland and Latvia. Journal of Industrial Microbiology and Biotechnology 31: 489-494.

Mampel J., T. Spirig, S.S. Weber, J.A.J. Haagensen, S. Molin and H. Hilbi. 2006. Planktonic replication is essential for biofilm formation by Legionella pneumophila in a complex medium under static and dynamic flow conditions. Appl. Environ. Microbiol. 72: 2885-2895.

Martiny A. C., T. M. Jørgensen, H.J. Albrechtsen, E. Arvin and S. Molin. 2003. Long-Term succession of structure and diversity of a biofilm formed in a model drinking water distribution system. Appl. Environ. Microbiol. 69: 6899-6907.

McBain A.J., R.G. Bartolo, C.E. Catrenich, D. Charbonneau, R.G. Ledder, A.H. Rickard, S.A. Symmons and P. Gilbert. 2003. Microbial characterization of biofilms in domestic drains and the establishment of stable biofilm microcosms. Appl. Environ. Microbiol. 69: 177-185.

Niquette P., P. Servais and R. Savoir. 2000. Impacts of pipe materials on densities of fixed bacterial biomass in a drinking water distribution system. Water Res. 34: 1952-1956.

Önorm B. 5018-1, 2002. 2 Prüfung der Verkeimungseigung Trinkwasserrohren, Teil 1: Prüfverfahren, Teil 2: Bewertung. Österreichisches Normungsinstitut, 1020 Wien.

Rosmaninho R., O. Santos, T. Nylander, M. Paulsson, M. Beuf, T. Benezech, S. Yiantsios, A. Andritsos, A. Karabelas, G. Rizzo and others. 2007. Modified stainless steel surfaces targeted to reduce fouling: Evaluation of fouling by milk components. J. Food Eng. 80: 1176-1187.

Squirrell D.D., R.L. Price and M.J. Murphy. 2002. Rapid and specific detection of bacteria using bioluminescence. Anal. Chem. Acta 457: 109-114.

Szczotko M., B. Krogulska and A. Krogulski. 2008. Elaboration of method for assessment of susceptibiliti to microbial growth of materials contacting with drinking water (in Polish). Roczn. PZH 59: 103-111.

Szczotko M., B. Krogulska and A. Krogulski. 2009. Investigation of susceptibility of materials contacting with drinking water for microbial growth (in Polish). Roczn. PZH 60: 137-142.

van der Kooij D., H.-J. Albrechtsen, C.B. Corfitzen, J. Ashworth, I. Parry, Enkiri, B. Hambsch, C. Hametner, H.R. Kloiber , H.R. Veenendaal, et al. 2003. CPDW project - Assessment of the microbial growth support potential of products in contact with drinking water.

van der Kooij D. and H.R. Veenendaal. 2001. Biomass production potential of materials in contact with drinking water: method and practical importance. Water Science \& Technology: Water Supply 1: 39-45.

van der Kooij D., H.R. Veenendaal, C. Baars-Lorist, D.W. van der Klift and Y.C. Drost. 1995. Biofilm formation on surfaces of glass and teflon exposed to treated water. Water Res. 29: $1655-1662$.

Zacheus O.M., E.K. Iivanainen, T.K. Nissinen, M.J. Lehtola and P.J. Martikainen. 2000. Bacterial biofilm formation on polyvinyl chloride, polyethylene and stainless steel exposed to ozonated water. Water Res. 34: 63-70. 